\title{
RESEARCH PAPER \\ LOWERED SERUM TRIGLYCERIDE LEVELS AMONG CHRONIC HEPATITIS B-INFECTED PATIENTS IN GHANA
}

\author{
J. K. Kwarteng ${ }^{1}$, L. Owusu ${ }^{1}$, M. Afihene ${ }^{2}$, E. Mica ${ }^{2}$, O. Opare-Sem ${ }^{2}$ and F. K. N Arthur ${ }^{1}$ \\ ${ }^{I}$ Dept. of Biochemistry and Biotechnology, College of Science, KNUST, Kumasi \\ ${ }^{2}$ Department of Medicine, Komfo Anokye Teaching Hospital (KATH), Kumasi
}

\begin{abstract}
Dyslipidemia is a common finding in most studies of liver diseases. Little is however known about the effect of the two pathological stages of chronic hepatitis $B(C H B)$ infection - chronicsymptomatic and asymptomatic - on the distribution of serum lipids in CHB infection. We conducted a study on CHB-infected patients attending specialist care at the Gastro-Intestinal (GI) Clinic at the Komfo Anokye Teaching Hospital (KATH) during a 7-month period. 64 participants were randomly sampled over the period. On the basis of serological and liver enzyme assays, participants were categorised as chronic asymptomatic, chronic symptomatic and healthy individuals. The relationship between the hosts pathological stage of infection were evaluated with the indices of lipid metabolism - LDL, HDL, triglyceride, and total serum cholesterol using ANOVA. The 64 volunteers recruited in the study were found to consist of 18 patients (28.1\%) who were chronic symptomatic, 35 patients $(54.7 \%)$ who were chronic asymptomatic hepatitis $B$, and $11(17.2 \%)$ were healthy subjects. Significant overall male dominance was observed among all categories of population enrolled $(p=0.0063)$. Serum triglyceride levels decreased more among the CHB-infected population compared to the healthy individuals $(p=0.0010)$ with value lowest among the chronic symptomatic population. Basal serum cholesterol, $H D L$, and LDL were unaffected by the disease. This work reveals that serum triglyceride is significantly lowered in CHB infection and that the extent of this decrease in host is independent of the pathological stage of the infection.
\end{abstract}

Keywords: chronic hepatitis B, lipid metabolism, triglyceride, chronic symptomatic

\section{INTRODUCTION}

Hepatitis B virus (HBV) infection is a serious global health problem, with 2 billion people infected worldwide, and 350 million suffering from chronic HBV infection of which nearly $500,000-1.2$ million die annually due to chronic hepatitis, cirrhosis, and hepatocellular carcinoma, and other liver-related complica- tions (WHO, 2000). Mortality due to liver diseases ranks fifth worldwide even though it ranks higher in developing countries like Ghana where viral hepatitis infection (hepatitis B and or $\mathrm{C}$ ) is very endemic with $\approx 15 \%$ with rate (Sarkodie et al., 2001).

The nature and extent of association of chronic 


\section{$2 \quad$ Kwarteng et al.}

hepatitis B disease and plasma metabolite dysregulation has become the subject of interest by most biomedical researchers over the past decade. The liver as a homeostatic organ plays a pivotal role in modulating endogenous and exogenous cycles of lipid metabolism. It is involved in the sequestration, remodelling (synthesis or recycling), and redistribution of lipid metabolites including lipoproteins such as low-density lipoproteins (LDL), high-density lipoproteins (HDL), and their corresponding apolipoproteins - ApoB, and Apo A1, etc., triglycerides (TG), and total plasma cholesterol. Thus the extracellular circulating levels of these metabolites in plasma depend significantly on the functional integrity of the hepatic tissues. Mild to severe liver deranging factors such as chronic hepatitis B infection could potentially interfere directly or indirectly with the levels of these lipid substrates in the plasma of infected hosts. Similarly, the chronic pro-inflammatory cytokine surge that characterise most cases of chronic hepatitis B could as well alter plasma lipid distribution. Such cytokines including tumor necrosis factor - alpha (TNF- $\alpha$ ), interferon $-\alpha($ IFN- $\alpha$ ) and IFN- $\gamma$, interleukin (IL)-1, IL-2, and IL-6 directly exert their influence on lipid metabolic pathways in the liver (Michiel and Oppenheim, 1992; Argiles et al., 1989; Kwong et al., 1997; Navasa et al., 1998).The effect of cytokines on serum lipid metabolism is often a direct one and not hormone-mediated which involves concerted signalling factors and intermediates. Most pro-inflammatory cytokines generally increase lipogenesis, very low density lipoprotein (VLDL) production and consequently increase in circulating LDL levels in serum. On the other hand, they decrease hepatic lipase activity in vitro (Feingold et al., 1992; Feingold and Grunfeld, 1987; Feingold et al., 1989; Nonogaki et al., 1995).

Dyslipidemia in liver diseases, as reported by most researchers, has been largely attributed to the decrease in the biosynthetic and bioprocessing capacity of the liver in diseased state as with chronic hepatitis B infection. Reports on the profile of lipids in cases of liver diseases have been very diverse showing slight to marked variations in plasma lipoprotein and apolipoprotein patterns. In one study of the dyslipidemia in chronic hepatitis, liver cirrhosis and hepato-cellular carcinoma, the TG and cholesterol levels decreased while LDLcholesterol fraction increased with HDLfraction remaining fairly unchanged. Metastatic liver cancer however showed a lower serum HDL-fraction compared to hepato-cellular carcinoma where higher levels of HDL, total cholesterol, and triglycerides were observed (Ooi et al., 2005). Su et al. (2004) reported a marked elevation of serum ALT as a correlate to lower levels of HDL-cholesterol (HDL-C) in patients with asymptomatic chronic hepatitis $\mathrm{B}$, and also as a correlate to lower serum HDL-C and higher TG levels in patients without HBV infection. Altogether, the increased LDL-C and the lower plasma HDL-C may pose increased cardiovascular risk to patients of liver disease.

Most researchers report of slight to major increase in serum levels of apolipoproteins and lipoproteins in patients suffering from various liver diseases (Su et al., 2004; Jiang et al., 2008). In one recent study, Jiang et al, (2008) reported of decreased apolipoprotein-A1 (ApoA1) and lipoprotein- $a(\mathrm{Lp}(\mathrm{a}))$ levels in patients suffering from hepatocellular carcinoma. In the same study, they found very high levels of ApoM proteins among patients suffering from chronic hepatitis B, HCC, and liver cirrhosis.

Pathophysiologically, there are two main stages of chronic hepatitis B infection - chronic symptomatic (fulminant chronic hepatitis B infection) and chronic asymptomatic stage with their attendant pathological manifestations. However, most studies of dyslipidemia involving chronic hepatitis $\mathrm{B}$ infection have not investigated the bearing of these stages on lipid profile of infected hosts. The aim of this study therefore was to assess the effect of these stages of chronic hepatitis B infection on distribution of plasma lipids. 


\section{PATIENTS AND METHODS}

Subjects and Sample collection

Between September 2009 and March 2010, 64 volunteers were randomly recruited. Altogether, they included 35 patients with asymptomatic CHB (22 males and 13 females, median age: $30 y r s$, age range: $23-44 \mathrm{yrs}), 18$ patients with symptomatic CHB (15 males and 3 females, median age: 35 years, age range: $23-47$ yrs), on admission or attending specialist care at the GI Clinic, Out-patient Department of the Komfo Anokye Teaching Hospital (KATH). Eleven apparently healthy individuals from the university campus (8 males and 3 females, median age: 26 years, age range: $23-29$ years) who tested seronegative for the HBsAg and $\mathrm{HBcAg}$ were randomly recruited as negative controls. The study was approved by the Committee on Human Research, Ethics, and Publications, School of Medical Science, KNUST Kumasi, and signed or thumb-printed informed consent was received from each volunteer prior to enrollment. $10 \mathrm{ml}$ intravenous blood drawn from volunteers were allowed to clot in sterile non-heparinised blood tubes and centrifuged at $3000 \mathrm{r} / \mathrm{min}$ for 10 minutes. The serum was collected into new vials and stored at $-28^{\circ} \mathrm{C}$ until use.

\section{Inclusion criteria}

Except for healthy controls, all other volunteers were recruited on the basis that they had chronic hepatitis B infection and have lived with it for at least six months after certified clinical diagnosis and awareness. Healthy controls had no clinical history of HBV-infection.

\section{Exclusion criteria}

1. Patients with records of alcoholism, smoking, or suggested dependence on herbal concoction in the week of the recruitment were not considered for the study.

2. Cohorts that had clinical records of cocomitant illnesses such as diabetes mellitus, hypertension, and other endocrine disorders were all excluded
Hepatitis virus markers and virologic studies HBsAg, antibody to HBsAg (anti-HBs), $\mathrm{HBeAg}$, and anti-HBeAg were assayed with commercial kits (AxSYM System, Abbott Laboratories, North Chicago, IL).

\section{Serum transaminase assay}

Serum levels of alanine and aspartate transaminases (ALT and AST) were assayed by a semiautomated approach using commercial Fortress ${ }^{\circledR}$ test kits (Fortress Diagnostics Ltd., Antrim BT41 1QS, UK) and Humalyzer Jnr. 18050 chemistry analyzer (Human Diagnostica, Germany). Patients were grouped into two categories based on their serum AST and ALT levels and HBV-serology namely: CHBasymptomatic (anti-HBcAg +ve, HBsAg +ve, and serum AST and ALT $\leq 40 \mathrm{IU} / \mathrm{l}$ ) or $\mathrm{CHB}$ symptomatic (anti-HBcAg +ve, HBsAg +ve, serum AST and ALT $\geq 40$ IU/l). Healthy individuals were anti-HBcAg -ve, HBsAg -ve, and had serum AST and ALT $\leq 40$ IU/l.

\section{Serum lipid profile}

Total serum cholesterol, LDL-, HDLcholesterol (HDL-C), and triglycerides (TG) were determined by a Humalyzer Jnr. 18050 chemistry analyzer (Human Diagnostica, Germany) using commercial Fortress ${ }^{\circledR}$ test kits (Fortress Diagnostics Ltd., Antrim BT41 1QS, UK). Blood samples were collected in the morning after a $12 \mathrm{hr}$ fast by venipuncture.

\section{Statistical analysis}

All data are expressed as mean \pm S.D. Statistical differences between the levels of the individual lipid indices among the three population sets were analysed through Student's $t$-test or ANOVA where necessary and all $p$ values < 0.05 were considered significant.

\section{RESULTS}

The age, gender, and basal serum transaminases (AST and ALT) levels, as clinical features of the population as determined are summarized in Table 1 . The healthy control volunteers enrolled in the study were considerably younger in comparison with the CHB-infected popu- 
lation even though the mean age distribution among the categories of the population was found to be insignificant $(p=0.3679)$. Table 1 also shows significant overall male dominance compared to females among the categories of the population enrolled $(p=0.0063)$ even though sampling was randomly done. As anticipated, there was a significant elevation of serum transaminases (AST and ALT) levels among the chronic symptomatic CHB patients compared to the asymptomatic and healthy cohorts as shown in Table $1(p=<0.0001)$. The AST/ALT ratio among the healthy subjects was almost five to ten-fold less than those of the CHB-infected patients $(p=0.0002)$.
There was a significant decline in basal serum triglyceride levels (hypotriglycerideamia) among the CHB-infected cohorts compared to those of the healthy control $(p=0.0010)$ as shown in Table 2. There was however no significant variation in the serum triglyceride distribution among the CHB disease stageschronic symptomatic and chronic asymptomatic - $(p=0.3569)$. Measured serum total cholesterol, HDL, and LDL levels did not differ significantly among the categories of cohorts enrolled for investigation in the study (Table 2). No significant difference was observed in the coronary risk among the $\mathrm{CHB}$ - infected cohorts and the healthy control $(p=0.1460)$.

Table 1: Age, gender, and selected LFT parameters of volunteers enrolled in the study

\begin{tabular}{|c|c|c|c|c|}
\hline Parameter & $\begin{array}{l}\text { Chronic } \\
\text { symptomatic } \\
n=18\end{array}$ & $\begin{array}{l}\text { Chronic } \\
\text { asymptomatic } \\
n=35\end{array}$ & $\begin{array}{l}\text { Healthy control } \\
n=11\end{array}$ & $P$-value \\
\hline Age (years) & $34.8 \pm 12.49$ & $33.0 \pm 10.5$ & $22.54 \pm 1.90$ & 0.3679 \\
\hline \multicolumn{5}{|l|}{ Gender } \\
\hline Male $(\%)$ & $15(83.3 \%)$ & $22(62.9 \%)$ & $8(72.7 \%)$ & 0.0063 \\
\hline Female $(\%)$ & $3(16.70 \%)$ & $13(37.1 \%)$ & $3(27.3 \%)$ & \\
\hline ALT (IU/L) & $161.9 \pm 18.10^{\mathrm{a}}$ & $12.3 \pm 6.45^{\mathrm{a}}$ & $25.6 \pm 5.21$ & $<0.0001^{\mathrm{a}}$ \\
\hline AST (IU/L) & $281.89 \pm 16.40^{b}$ & $29.21 \pm 5.13^{b}$ & $9.50 \pm 2.91$ & $<0.0001^{\mathrm{b}}$ \\
\hline AST/ALT Ratio & $5.659 \pm 1.12^{\mathrm{c}}$ & $2.591 \pm 0.34^{\mathrm{c}}$ & $0.363 \pm 0.08$ & $0.0002^{\mathrm{c}}$ \\
\hline
\end{tabular}

$n=$ number of subjects

${ }^{a, b, c}=$ significant at $p \leq 0.05$

Table 2: Lipid indices among the CHB -infected patients and healthy control

\begin{tabular}{|c|c|c|c|c|}
\hline Plasma Lipid Indices & $\begin{array}{l}\text { Chronic } \\
\text { symptomatic } \\
n=18\end{array}$ & $\begin{array}{l}\text { Chronic } \\
\text { asymptomatic } \\
n=35\end{array}$ & $\begin{array}{l}\text { Healthy } \\
\text { control } \\
n=11\end{array}$ & $P$-value \\
\hline Total cholesterol (mmol/l) & $5.19 \pm 3.06$ & $5.38 \pm 1.22$ & $4.70 \pm 0.71$ & 0.6080 \\
\hline Triglyceride (mmol/l) & $0.76 \pm 0.60^{\mathrm{a}}$ & $1.12 \pm 0.73^{\mathrm{a}}$ & $1.69 \pm 0.83$ & 0.0010 \\
\hline HDL (mmol/l) & $1.33 \pm 0.69$ & $1.70 \pm 0.54$ & $1.92 \pm 0.16$ & 0.0970 \\
\hline LDL (mmol/l) & $4.83 \pm 0.71$ & $4.39 \pm 1.01$ & $3.98 \pm 1.12$ & 0.7470 \\
\hline Coronary risk (HDL/LDL ratio) & $0.33 \pm 0.17$ & $0.40 \pm 0.17$ & $0.51 \pm 0.15$ & 0.1460 \\
\hline
\end{tabular}

$n=$ number of subjects,${ }^{a} P>0.05$ 


\section{DISCUSSION}

Dyslipidemia has been a recurrent finding from reports of most studies on metabolic complications associated with liver diseases. In one study, Bedimo et al. (2006) reported marked plasma lipid abnormalities associated with patients with HCV and HIV coinfection. In another study, it was concluded that plasma levels of triglycerides, cholesterol, free fatty acids, HDL, LDL, apolipoproteins including - Apo A, and Apo B and the lipoprotein $a(\operatorname{Lp}(a))$, were decreased in hepato-cellular carcinoma. It was suggested that this may be due to hepatocellular impairment and indicated poor prognosis (Jiang et al., 2006). Additionally, Mastoi et al. (2010) showed that serum total cholesterol levels (HDL-, LDL-cholesterol) were significantly decreased in hepatitis $\mathrm{B}$ and $\mathrm{C}$ infected population compared to the control. Also, whereas serum triglyceride was significantly decreased in $\mathrm{HCV}$-infected cohorts, it remained unchanged among HBV-infected population.

The study reveals a marked gender disparity in the progression of the chronic hepatitis B infection among hosts despite the random sampling. This indicates that the virus interacts to different extent with male and female genetic and physiological factors. Similar results have been observed in several studies of both human and transgenic mice populations with the latter showing a more overt and stronger gender bias in a ratio of 5-7:1 between male and female respectively as compared to humans ( $\mathrm{Yu}$ and Chen., 1994; Wang et al., 2004; Yuen et al., 2008). Proteomic and genomic studies have shown that the Hepatitis B X protein (HBXP), one of the important HBV antigens, potentiates androgen receptor activity by increasing signal activation of the receptors via phosphorylation (Chiu et al., 2007). In addition, viral antigen expression has been found to suppress apolipoprotein A1 (Apo - A1) levels in vivo in males than in females according to one study using transgenic mice (Yang et al., 2010). The ApoA1 plays a critical role in immune resistance hence suppression of its expression indicates a compromised immunity and increased suscepti- bility in host. This may account for the observed male susceptibility to the chronic HBV disease progression among the studied $\mathrm{CHB}$ cohorts.

There is an established fact that basal serum AST and ALT are of immense diagnostic value especially in evaluating suspected liver dysfunction (Sheth et al., 1998; Sorbi et al., 1999). These enzymes are compartmentalized in the hepatocytes where they play critical role in nitrogen recycling. Often, the rate of necrosis of the hepatocytes increases in liver diseases as with chronic hepatitis $\mathrm{B}$ infection through diverse molecular signalling and interaction. As the hepatocytes die, their intracellular enzymes such as transaminases (AST and ALT) leak into the extracellular matrix of the hepatic tissue and eventually diffuse into the blood circulation. Due to the constant turn-over of worn-out hepatocytes in the body, there always exists some tolerable amount of these enzymes in the sera. The normal ranges of these enzymes are as follows: AST $2-35 \mathrm{IU} / \mathrm{ml}$ and ALT 2 $40 \mathrm{IU} / \mathrm{ml}$. Hence the instantaneous serum levels of the enzymes AST and ALT is predictive of the presence or absence of liver disease. Generally, elevated AST and ALT levels are suggestive of mild to severe liver damage due to cirrhosis, hepatitis, alcoholism, and hepatocellular carcinoma. The greater extent of cirrhosis among the chronic symptomatic patients may account for their observed higher AST and ALT levels relative to those of the healthy control cohorts as recorded in Table 1.

Whereas the serum levels of the enzymes AST and ALT are predictive of the presence or absence of liver disease, their ratio (AST/ALT) gives more insight into the functional integrity of the diseased liver. In one study reported by Sorbi et al. (1999), there was a profound overlap of AST/ALT ratio among steatohepatitis patients. During the study of the 140 patients with nonalcoholic steatohepatitis (NASH; confirmed by liver biopsy) or alcoholic liver disease, a mean AST/ALT ratio of 0.9 in patients with NASH and 2.6 in patients with alcoholic 
liver disease was observed (ibid). Within the population studied, 87 percent of patients with an AST/ALT ratio of 1.3 or less had NASH (87 percent sensitivity, 84 percent specificity). Altogether, they found that AST/ALT ratio increased with increased severity of the NASH as measured by the degree of fibrosis. A mean ratio of 1.4 was found in patients with cirrhosis related to NASH. These varying ratios further reinforce their potential clinical utility at helping in classifying various forms of liver diseases pertaining to steatohepatitis and alcoholic liver disease (ibid).

This study showed averagely higher AST/ALT ratio among the CHB-infected population compared to the healthy control perhaps due in part to mild to significant hepatic cirrhosis among the CHB-infected cohorts. As expected, the average AST/ALT ratio of the chronic symptomatic patients diagnosed with severe cirrhosis was twice (5.659) as higher as that for the asymptomatic patients (2.591) diagnosed with minor cirrhosis. Several studies have also shown that AST/ALT ratio increases above 1 in most cases of chronic liver diseases including chronic active hepatitis B (McClatchey, 2002). It is suggested that, irrespective of the aetiology, the AST/ALT ratio increases above 1 in cases of liver cirrhosis (William and Hoofnagle, 1988; Mastoi et al., 2010). Even though the reason for this observation is unknown, it has been suggested that sinusoidal clearance of serum AST decreases in progressive cirrhosis condition leaving the basal AST levels far in excess of the ALT (Nyblom et al., 2004; Nyblom et al., 2006; Park et al., 2000; Alempijevic et al., 2009). In end-stage liver disease, the enzyme levels fall to normal or subnormal levels as functional hepatocytes become depleted due to progressive necroinflammation in the damaged liver. Hence, in most end-stage liver diseases, AST/ALT ratio is 1 . These findings confirm the usefulness of the ratio as an adjunct index for monitoring extent of cirrhosis among the CHB-infected population prior to the terminal stage of the disease where there is permanent liver decompensation.
The results from Table 2 is consistent with the reported works of Ianello et al. (2003) and Luo et al. (2007) who showed an inverse correlation between $\mathrm{HBV}$-infection and elevated serum triglyceride levels even though their studies were carried out in different geographical locations and settings. Upon infection, the viral $\mathrm{X}$ protein $(\mathrm{HBxP})$ interacts with host hepatic metabolic genes such as sterol regulator element binding protein-1 (SREBP-1), carbohydrate regulator element binding protein (ChREBP), peroxisome proliferator activator receptor-gamma (PPAR- $\gamma$ ), among others.

The consequence of this interaction is to switch hepatic metabolism from fatty acid synthesis and secretion via lipoproteins to increased hepatic lipid synthesis and storage (Shlomai and Shaul, 2009; Kim et al., 2007). Thus the liver becomes more adipogenic sequestering most of the lipids that diffuse into it. This scenario creates a steatotic condition in the infected liver as have been reported by some researchers (Altiparmak et al. 2005; Thormopuolos et al., 2006; Tsochatzis et al. 2007; and Cindoruk et al., 2007). This may account in part for the observed decreased circulating triglyceride in serum of the hepatitis B infected population in relation to the healthy control. Even though the liver is thought of as the central player in regulation of lipid metabolism, it must be emphasized that the liver does so through effective coordination with other auxiliary organs and tissues from the body by means of chemical messengers in the form of cytokines and steroid hormones. These exocrine and endocrine messengers may modulate, potentiate, or synergize to varying extent with the homoeostatic functions of the HBV infected liver in controlling circulating lipid levels in sera of hosts. Hence, dysregulation of these factors due to the chronic HBV infection can partly be implicated for the observed distortions in the serum lipid distribution. This may account for the marginally lower triglyceride levels among the chronic symptomatic patients even though not statistically significant $(p=0.3569)$. 
The prolonged surge in proinflammatory cytokines such as TNF-alpha, IL-1, IL-6, IFN- $\alpha$, etc. observed following the chronic state of the HBV-infection (Argiles et al., 1985; Grunfeld et al., 1991; Naeem et al., 2001; Khovidhunkit et al., 2004) could have contributed to the observed distortions in the various lipid indices of the hepatitis B-infected population. Cytokines such as the TNF- $\alpha$, IL-1, IL-6, IFN- $\alpha$, etc. have been reported to increase lipogenesis, decrease clearance of circulating LDLs, and inhibit hepatic lipase activity (Feingold et al., 1992; Feingold and Grunfeld, 1987; Feingold et al., 1989; Nonogaki et al., 1995). This probably accounts for the observed slight increase in the serum LDL levels among the HBV-infected populations as shown in Table 2. The decreased HDL levels may be due to the decrease in ApoA1 secretion in the hepatitis B-infected patients with cirrhosis (Lee et al., 2010). Total serum cholesterol is largely based on the cholesterol contents of HDL and LDLs. The observed slight increase in cholesterol among the chronic hepatitis B-infected cohorts from Table 2 might be due to the contribution by the LDL fraction.

\section{CONCLUSION}

In conclusion, significant hypotriglycerideamia occurs among chronic hepatitis B-infected patients in Kumasi, Ghana. Even though there is enough literature to account for the mechanism of decreased serum triglyceride levels in chronic hepatitis B-infected hosts, the essence of this phenomenon whether as a viral survival strategy or mere pathological consequence remains to be established.

\section{Acknowledgement}

This study was supported by a grant from the Research and Conference Committee, Kwame Nkrumah University of Science and Technology, Kumasi-Ghana (KNUST). The authors also give due acknowledgements to both Heads of the Clinical Biochemistry and Immunodiagnostic Departments at the Komfo Anokye Teaching Hospital, (KATH), Kumasi for providing working space for this study.

\section{REFERENCES}

Alempijevic, T., Krstic, M., Jesic, R., Jovanovic, I., SokicMilutinovic, A., Kovacevic, N., Krstic, S. and Popovic, D. (2009). Biochemical markers for non-invasive assessment of disease stage in patients with primary biliary cirrhosis. World J. Gastroenterol., 15(5): 591 -594 .

Altiparmak, E., Koklu, S. and Yalinkilic, M. (2005).Viral and host causes of fatty liver in chronic hepatitis B. World J. Gastroenterol., 11: 3056-9.

Argiles, J. M., Lopez-Soriano, F. J., Evans, R. D. and Williamson, D. H. (1989). Interleukin - 1 and lipid metabolism in the rat. Biochem J., 259(3):673-678.

Bedimo, R., Ghurani, R., Nsuami, M, Turner, D., Kvanli, M.B., Brown, G. and Margolis, D. (2006). Lipid abnormalities in HIV/ hepatitis $\mathrm{C}$ virus-confected patients. HIV Medicine, 7(8): 530-536.

Chiu, C. M., Yeh, S. H., Chen, P. J., Kuo, T. J., Chang, C. J., Chen, P. J., Yang, W. J. and Chen, D. S. (2007). Hepatitis B virus X protein enhances androgen receptor-responsive gene expression depending on androgen level. Proc. Natl. Acad. Sci., 104 (8): 25718 .

Cindoruk, M., Karakan, T. and Unal, S. (2007). Hepatic steatosis has no impact on the outcome of treatment in patients with chronic hepatitis B infection. J. Clin. Gastroenterol., 41:513-17.

Feingold, K. R.and Grunfeld, C. (1987). Tumor necrosis factor-alpha stimulates hepatic lipogenesis in the rat in vivo. J. Clin. Invest., 80 : 184-190.

Feingold, K. R., Soured, M., Serio, M. K., Moser, A. H., Dinarello, C. A. and Grunted, C. (1989). Multiple cytokines stimulate hepatic lipid synthesis in vivo. Endocrinology 
125: 267-274.

Feingold, K. R., Staprans, I, Memo, R. A., Moser, A. H., Shigenaga, A. J., Doerrler, W., Dinarello, C. A. and Grunfeld, C. (1992). Endotoxin rapidly induces changes in lipid metabolism that produce hypertriglyceridemia: low doses stimulate hepatic triglycerideproduction while high doses inhibit clearance. J. Lapidaries., 33: 1765-1776.

Grunfeld, C., Donatello, C. A. and Feingold, K. R. (1991). Tumor necrosis factor $-\alpha$, interleukin -1 , and interferon $-\alpha$ stimulate triglyceride synthesis in HepG2 cells. Metabolism, 40 (90):894-898.

Iannello, S., Cavaleri, A. and Milazzo, P. (2003). Low fasting serum triglyceride level as a precocious marker of autoimmune disorders. Med Gen Med., 5:20.

Jiang, J., Nilsson-Ehle, P. and Xu, N. (2006). Influence of liver cancer on lipid and lipoprotein metabolism. Lipids health Dis., 5:4.

Jiang, J., Zhang, X., Wu, C., Qin, X., Luo, G., Deng, H., Lu, M., Xu, B., Li. M., Ji, M. and $\mathrm{Xu}, \mathrm{N}$. (2008). Increased plasma apoM levels in the patients suffered from hepatocellular carcinoma and other chronic liver diseases. Lipids in Health and Disease, 7: 25.

Khovidhunkit, W., Kim, M. S., Memon, R. A., Shigenaga, J. K., Moser, A. H., Feingold, K. R. and Grunfeld, C. (2004). Effects of infection and inflammation on lipid and lipoprotein metabolism: mechanisms and consequences to the host. J. Lipid Res., 45:11691196.

Kim, K. H., Shin, H. J. and Kim, K. (2007). Hepatitis $\mathrm{B}$ virus $\mathrm{X}$ protein induces hepatic steatosis via transcriptional activation of SREBP1 and PPAR-gamma. Gastroenterology, 132: 1955-67.

Kwong, L. K., Ridinger, D. N., Bandhauer, M.,
Ward, J. H., Samlowski, W. E., Iverius, P. H., Pritchard, H. and Wilson, D. E. (1997). Acute dyslipoproteinemia induced by interleukin2:lecithin:cholesterylacyltransfera se, lipoprotein lipase, and hepatic lipase deficiencies. J Clin Endocrinol Metab., 82 (5):1572-1581.

Lee, K. G., Seo, S. Y., An, H., Um, S. H., Jung, E. S., Keum, B., Yim, H. J., Jeen, T. Y., Chun, H. J., Kim, C. D. and Ryu, H. S. (2010). Usefulness of non-invasive markers for predicting liver cirrhosis in patients with chronic hepatitis B. J. Gastroenterol. and Hepatol., 25:94-100.

Luo, B., Wang, Y. and Wang, K. (2007). Association of metabolic syndrome and hepatitis B infection in a Chinese population. Clinica Chimica Acta., 380: 238240 .

Mastoi, A. A., Devrajani, B. R., Shah, S. Z. A., Rohopoto, Q., Memon, S. A., Baloch, M., Qureshi, G. A. and Sami, W. (2010). Metabolic investigations in patients with hepatitis B and C. World J Gastroenterol. 16 (5): 603-607.

McClatchey, K. D. (2002). Clinical laboratory medicine. Lippincott Williams and Wilkins. pp. 288.

Michiel, D. F. and Oppenheim, J. J. (1992). Cytokines as positive and negative regulators of tumor promotion and progression. Semin. Cancer Biol., 3 (1):3-15.

Naeem, M., Bacon, B. R., Mistry, B., Britton, R. S. and Di Bisceglie, A. M. (2001). Changes in serum lipoprotein profile during interferon therapy in chronic hepatitis C. Am. J. Gastroenterol., 96: 2468-2472.

Navasa, M., Gordon, D. A., Hariharan, N., Jamil, H., Shigenaga, J. K., Moser, A., Fiers, W., Pollock, A., Grunfeld, C. and Feingold, K. R. (1998). Regulation of mi- 
crosomal triglyceride transfer protein mRNA expression by endotoxin and cytokines. $J$ Lipid Res., 39 (6): 1220-1230

Nonogaki, K., Fuller, G. M., Fuentes, N. L., Moser, A. H., Staprans, I., Grunfeld, C. and Feingold, G. R. (1995). Interleukin-6 stimulates hepatic triglyceride secretion in rats. Endocrinology, 136:2143-2149.

Nyblom, H., Berggren, U., Balldin, J. and Olsson, R. (2004). High AST/ALT ratio may indicate advanced alcoholic liver disease rather than heavy drinking. Alcohol, 39:336339.

Nyblom, H., Bjornsson, E., Simren, M., Aldenborg, F., Almer, S. and Olsson, R. (2006). The AST/ALT ratio as an indicator of cirrhosis in patients with PBC. Liver Int., 26:840845

Ooi, K., Shiraki, K., Sakurai, Y., Morishita, Y. and Nobori, T. (2005). Clinical significance of abnormal lipoprotein patterns in liver diseases. Int J Mol Med., 15 (4):655-60.

Park, G. J., Lin, B. P., Ngu, M. C., Jones, D. B. and Katelaris, P. H. (2000). Aspartate aminotransferase: alanine aminotransferase ratio in chronic hepatitis $\mathrm{C}$ infection: is it a useful predictor of cirrhosis? J GastroenterolHepatol., 15: 386-390.

Sarkodie, F., Adarkwa, M., Adu-Sarkodie, Y., Candotti, D., Acheampong, J. W. and Allain, J. P. (2001). Screening for viral markers in volunteer and replacement blood donors in West Africa. Vox Sang., 80:142-147.

Sheth, S., Flamm, S. L. and Gordon, F. D. (1998). AST/ALT ratio predicts cirrhosis in patients with chronic hepatitis $\mathrm{C}$ virus infection. Am J Gastroenterol., 93:44-48.

Shlomai, A. and Shaul, Y. (2009).The metabolic activator FOXO1 binds hepatitis B virus DNA and activates its transcription; Bio- chemical and Biophysical Research Communications, 381:544-548.

Sorbi, D., Boynton, J. and Lindor, K. D. (1999). The ratio of aspartate aminotransferase to alanineaminotransferase: potential value in differentiating nonalcoholic steatohepatitis from alcoholic liver disease. Am J Gastroenterol., 94:1018-1022.

Su, T. C., Lee, Y. T., Cheng, T. J., Chien, H. P. and Wang J. D.(2004). Chronic hepatitis B virus infection and dyslipidemia. J Formos Med Assoc., 103(4):286-91.

Thomopoulos, K. C., Arvaniti, V. and Tsamantas, A. C. (2006). Prevalence of liver steatosis in patients with chronic hepatitis B: a study of associated factors and of relationship with fibrosis. Eur. J.Gastroenterol. Hepatol., 18:233 - 7 .

Tsochatzis, E., Papatheooridis, G. V. and Manesis, E. K. (2007). Hepatic steatosis in chronic hepatitis B develops due to host metabolic factors: a comparative approach with genotype 1 chronic hepatitis C. Dig. Liver Dis., 39:936-42.

Wang, Y., Cui, F., Lv, Y., Li, C., Xu, X., Deng, C., Wang, D., Sun, Y., Hu, G., Lang, Z., Huang, C. and Yang, X. (2004). HBsAg and HBx knocked into the $\mathrm{p} 21$ locus causes hepatocellular carcinoma in mice. Hepatology, 39 (2):318-24.

WHO.(2000). Hepatitis B. World Health Organization Fact Sheet 204.

Williams, A. L. and Hoofnagle, J. H. (1988). Ratio of serum aspartate to alanine aminotransferase in chronic hepatitis: Relationship to cirrhosis. Gastroenterology, 95:734739 .

Yu, M. W. and Chen, C. J. (1994). Hepatitis B and $\mathrm{C}$ viruses in the development of hepatocellular carcinoma. Crit. Rev. Oncol. Hema- 
tol., 17(2): 71-91.

Yuen, M. F., Tanaka, Y., Fong, D. Y., Fung, J., Wong, D.K. Yuen, J.C., But,D. Y., Chan, A. O., Wong, B. C., Mizokami, M. and Lai, C.
L. (2008). Independent risk factors and predictive score for the development of hepa tocellular carcinoma in chronic hepatitis B. $J$. Hepatol., 50 (1):7-9. 